DOI: 10.12957/demetra.2017.25127

\title{
Pães de mel elaborados com farinha de diferentes variedades de banana verde
}

\section{Honey Breads made with flour of different varieties of green banana}

\author{
Maria Cristina Jesus Freitas' \\ Gabrielle Esteves da Silveiral \\ Lívia Soares Veras' \\ Gabriela Fernandes Flauzino Santos' \\ 1 Universidade Federal do Rio de Janeiro, \\ Departamento de Nutrição Básica e Experimental. \\ Rio de Janeiro-RJ, Brasil. \\ Correspondência / Correspondence \\ Maria Cristina Jesus Freitas \\ E-mail: cristina@nutricao.ufri.br
}

\section{Resumo}

Objetivou-se desenvolver pães de mel com farinhas de banana verde cozida de duas variedades: prata (FBVCP) e nanicão (FBVCN), caracterizando-os física, química, físico-química e sensorialmente. As polpas de banana verde cozidas foram desidratadas em estufa ventilada a $65^{\circ} \mathrm{C} / 20 \mathrm{~h}$ e moídas, obtendo assim as Farinhas de Banana Verde Cozida. Foram desenvolvidas três formulações de pão de mel por modificação da formulação padrão $(\mathrm{P})$, com substituição parcial da farinha de trigo pelas FBVCP e FBVCN em $30 \%$ e com $15 \%$ de ambas as farinhas, sendo estes denominados, respectivamente, de pão de mel A, B e C. As análises físicas para FBVC foram os resíduos das perdas do processamento e o rendimento final. Já para os pães de mel peso, altura, e diâmetro antes e pós-cocção, densidade, fator térmico e rendimento, foram em amostras aleatórias constituídas de unidades provenientes de uma mesma fornada. As análises químicas e físico-químicas realizadas das farinhas e dos pães de mel foram: umidade, cinzas, fibra alimentar insolúvel (FAI), proteína, lipídios, Amido resistente (AR) e carboidratos (por diferença), acidez titulável e pH. Os pães de mel também foram analisados sensorialmente por provadores não treinados da universidade (Universidade Federal do Rio de Janeiro-UFRJ), aplicando o teste de preferência ordenação em 37 provadores e aceitação através da escala hedônica de nove pontos para os atributos aparência, aroma, textura, sabor e aspecto global em 73 provadores, com seu consentimento e aprovado pelo comitê de ética em Pesquisa da Universidade sob o número 164/07. Quanto às características físicas, os rendimentos das farinhas foram de $17 \%$, e para os pães de mel, a maior diferença $(\mathrm{p} \leq 0,05)$ expressou-se na redução da altura pós-cocção para as 
formulações com as farinhas devido ao elevado teor de fibra e AR nos pães. As FBVC prata e nanicão apresentaram umidade em conformidade com a legislação brasileira, elevado teor de AR, proteína, FA e cinzas. Os pães de mel elaborados com as farinhas, consequentemente, apresentaram perfil químico e nutricional superior ao do padrão e foram considerados alimentos fontes de FA e AR. A acidez titulável e o $\mathrm{pH}$ foram maiores $(\mathrm{p} \leq 0,05)$ para o pão de mel elaborado com a farinha da variedade nanicão. Todos os pães de mel foram considerados igualmente preferidos e obtiveram boa aceitação, com IA $\geq$ de $80 \%$ nos atributos avaliados. Conclui-se que a utilização das farinhas agregou valor nutricional e funcional, pois aumentou o teor de FA, AR, proteínas e minerais aos produtos, sem modificações das características sensoriais e com boa aceitação sensorial, propiciando qualidade sensorial e nutricional.

Palavras-chave: Banana verde. Farinha de banana verde. Pão de mel. Fibra alimentar. Amido resistente.

\section{Abstract}

The objective of this study was to develop honey buns with cooked green banana flours of two varieties: silver (FBVCP) and nanicão (FBVCN), characterizing them, physically, chemically, physicochemically and sensorially. The cooked green banana pulps were dehydrated in a ventilated oven at $65^{\circ} \mathrm{C} / 20 \mathrm{~h}$ and ground, thus obtaining the Cooked Green Banana Flour. Three formulations of honey bread were developed by modifying the standard formulation $(\mathrm{P})$, with partial substitution of the wheat flour by the FBVCP and FBVCN in $30 \%$ and with $15 \%$ of both flours, respectively called honey bread A, B and C. The physical analyzes for: FBVC were the residuals of the losses of the processing and the final yield. The weight, height, and diameter before and after cooking, density, thermal factor and yield were in random samples of units from the same batch. The chemical and physicochemical analyzes of flours and honey loaves were: moisture, ash, insoluble food fiber (FAI), protein, lipids, resistant starch (RA) and carbohydrates (by difference), titratable acidity and $\mathrm{pH}$. The honey loaves were also analyzed sensorially by untrained university tasters (UFRJ), applying the preference test ordering in 37 tasters and acceptance through the 9 point hedonic scale for the attributes appearance, aroma, texture, taste and overall appearance in 73 tasters, with their consent and approved by the research ethics committee of the University under number $164 / 07$. Regarding the physical characteristics, the yields of the 
flour were $17 \%$ and for the loaves of bread the highest difference $(\mathrm{p} \leq 0.05)$ was expressed in the reduction of the post-cooking height for the formulations with the flour due to the high content of Fiber and RA in the breads. The FBVC silver and nanicão presented humidity according to the Brazilian legislation, high content of RA, protein, FA and ash. The honey breads elaborated with the flour consequently presented chemical and nutritional profile higher than the standard and were considered food sources of FA and RA. The titratable acidity and the $\mathrm{pH}$ were higher $(\mathrm{p} \leq 0.05)$ for the bread of honey elaborated with the flour of the variety nanicão. All honey loaves were considered equally preferred and were well accepted, with $\mathrm{IA} \geq 80 \%$ in the evaluated attributes. It was concluded that the use of flour added nutritional and functional value, because it increased the FA, RA, protein and minerals content to the products, without modifications of the sensorial characteristics and with good sensory acceptance, providing sensorial and nutritional quality.

Keywords: Green banana. Green banana flour. Honey bread. Food fiber. Resistant starch.

\section{Introdução}

Durante as últimas décadas, pôde-se observar um crescente interesse do consumidor para produtos com fibra alimentar e amido resistente.

O amido resistente (AR) à hidrólise enzimática pode ser fisiologicamente definido como a soma do amido e produtos da degradação do amido não digerido/ absorvido no intestino delgado do indivíduo saudável, podendo, entretanto, ser fermentado no intestino grosso. ${ }^{1}$

O AR pode se elevar em produtos amiláceos quando os mesmos são submetidos ao processamento hidrotérmico drástico., ${ }^{2,3}$ Por outro lado, pode ser encontrado naturalmente em frutos verdes, ${ }^{3}$ a banana, por exemplo. ${ }^{4,5} \mathrm{O}$ fruto verde apresenta dureza e elevada adstringência, decorrente da presença de compostos fenólicos solúveis, deixando de ser apreciado pelos consumidores. ${ }^{6,7}$ Assim, a farinha de banana verde in natura ou cozida ainda é a melhor forma para sua utilização e consumo, evitando também o seu desperdício pós-colheita.

Na dieta, sua inclusão é vista como positiva por diversos estudos, fato que se encontra relacionado a sua composição nutricional ${ }^{6-8}$ em função do seu elevado teor de amido resistente e de sua ação biológica redutora sobre o índice glicêmico ${ }^{9}$ e seu papel para a saúde e integridade do cólon. ${ }^{10,11}$ A literatura tem apresentado o uso de farinhas de banana verde como opção de 
substituição para outras farinhas largamente utilizadas no Brasil, como a farinha de trigo, na elaboração de produtos alimentícios. ${ }^{12-16}$

Dessa forma, o presente trabalho teve por objetivo desenvolver pães de mel com farinhas de banana verde cozida de duas variedades: prata (FBVCP) e nanicão (FBVCN), caracterizando-os física, química, físico-química e sensorialmente.

\section{Metodologia}

\section{Matéria-prima}

Todo o trabalho experimental foi desenvolvido no complexo laboratorial (Laboratório Dietético e de Análise de Alimentos) do Instituto de Nutrição Josué de Castro, localizado no Centro de Ciências da Saúde da Universidade Federal do Rio de Janeiro.

As matérias-primas foram as bananas verdes da espécie Musa cavendishi, variedades prata e nanicão (d'água). Os frutos verdes foram adquiridos no mercado municipal do Rio de Janeiro, no mês de agosto de 2015, aproximadamente $16 \mathrm{~kg}$, entre os estágios 1 e 2 de maturação determinados através da escala de maturação de Von Loesecke. ${ }^{17}$ As bananas verdes foram retiradas dos cachos ainda com cascas e lavadas em água corrente para a retirada das sujidades físicas, como poeira, terra e folhas. Logo após, colocadas em solução clorada (132 gramas do sanitizante Bioclor a 0,66\% da marca Noordhen Brasil em 20 litros de água) por 20 minutos de acordo com instruções do fabricante. ${ }^{13}$

\section{Obtenção das farinhas de bananas verdes cozidas (FBVC)}

Os frutos verdes tiveram suas extremidades cortadas para facilitar a cocção, sendo tais extremidades reservadas para posterior contabilização dos resíduos e desprezadas após. As bananas foram dispostas em panelas de pressão submersas em água e submetidas à cocção por 20 minutos.

Após a cocção, foi realizada a separação da polpa e cascas das bananas, sendo estas contabilizadas e desprezadas. As polpas das bananas verdes cozidas foram então fracionadas em pedaços pequenos, amassadas e desidratadas em estufa a $65^{\circ} \mathrm{C}$ por 20 horas das massas das variedades prata e nanicão. ${ }^{13}$ Depois, foram moídas em moinho martelo, com lâmina de 0,75 mm por 3-5 minutos, para obtenção das farinhas (Figura 1). 


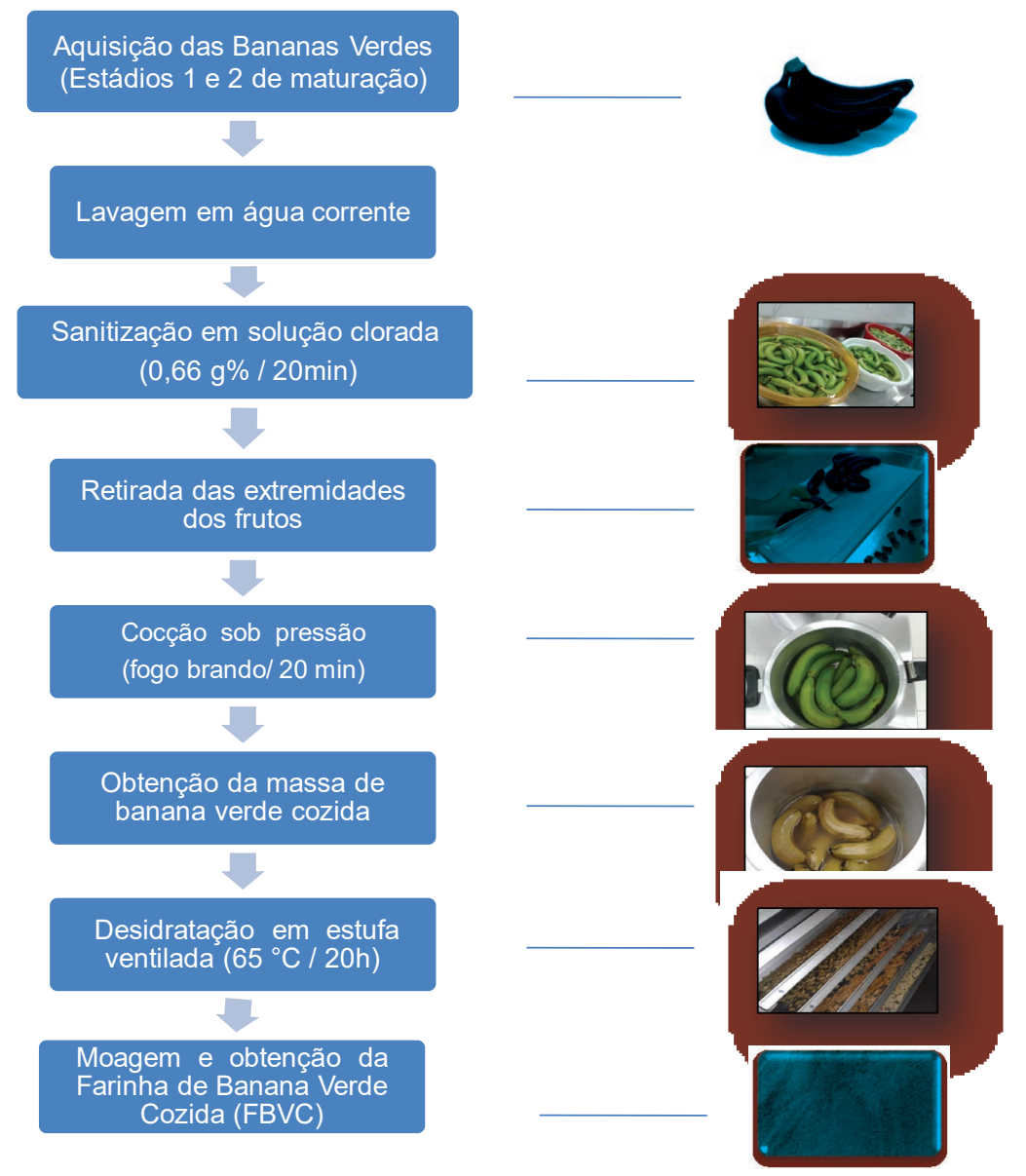

Figura 1. Fluxograma de obtenção da Farinha de Banana Verde Cozida.

As farinhas obtidas foram então acondicionadas em recipientes de vidro, devidamente identificados e armazenados em freezer $\left(-18{ }^{\circ} \mathrm{C}\right)$, para posterior análise e sua aplicação em formulações de pão de mel. 


\section{Análises físicas, químicas e físico-químicas das farinhas e dos produtos}

Entende-se como análise física das farinhas os pesos obtidos nas etapas do processamento do fruto (recolhidos resíduos) até obtenção final da farinha, bem como as características de aparência (cor e textura) das mesmas. Já a determinação dos parâmetros físicos dos pães de mel seguiram os procedimentos descritos por Silva et al., 2001: ${ }^{18}$ para o peso, altura e diâmetro antes e pós-cocção, densidade, fator térmico e rendimento, conduzidos com dez unidades provenientes de uma mesma fornada amostrados de forma aleatória assim que foram resfriados em temperatura ambiente.

As análises químicas e físico-químicas das farinhas e dos produtos, em triplicata, dos teores de umidade foram obtidas por método gravimétrico com emprego de calor, em estufa a 105ํㅡ até peso constante; das cinzas por incineração em mufla a $550^{\circ} \mathrm{C}$; da fibra alimentar total por método gravimétrico não enzimático com adição de acetona e álcool, em estufa a $105^{\circ} \mathrm{C}$ até peso constante; das proteínas, foram obtidas a partir da determinação de nitrogênio, pelo método de digestão Kjedahl, com conversão pelo fator 6,25 para obtenção da quantidade de proteína em gramas; dos lipídeos, foram determinados por extração contínua em solvente pelo método de Soxhlet; da acidez titulável, por método titulométrico com hidróxido de sódio $0,1 \mathrm{~N}$ e indicador fenolftaleína; o pH foi determinado por método eletrométrico - todas segundo as metodologias propostas pelo Instituto Adolfo Lutz. ${ }^{19} \mathrm{O}$ amido resistente foi obtido por Ramos, Leonel e Leonel. ${ }^{4}$ Os carboidratos foram determinados por diferença entre a massa total $(100 \mathrm{~g})$ e a soma dos demais componentes analisados (umidade, cinzas, fibra alimentar, proteínas, lipídios e amido resistente).

\section{Formulação dos produtos}

As formulações dos pães de mel estão na Tabela 1, assim como sua técnica de preparo. Foram desenvolvidas três formulações de pão de mel por modificação da formulação padrão $(\mathrm{P})$, com substituição parcial da farinha de trigo pelas FBVCP e FBVCN em 30\% e com 15\% de ambas as farinhas, sendo estes denominados, respectivamente, de pão de mel A, B e C. Após, receberam banho de chocolate e, consequentemente, refrigerados por 20 minutos. 
Tabela 1. Formulação dos pães de mel elaborados com farinhas de banana verde cozida, Rio de Janeiro-RJ, 2015.

\begin{tabular}{|c|c|c|c|c|}
\hline \multirow{2}{*}{ Ingrediente (g/mL) } & \multicolumn{4}{|c|}{ Formulações } \\
\hline & PADRÃO & $\mathrm{A}$ & $\mathrm{B}$ & C \\
\hline Farinha de trigo & 37,5 & 26,25 & 26,25 & 26,25 \\
\hline FBVCP & - & 11,25 & - & 5,625 \\
\hline FBVCN & - & - & 11,25 & 5,625 \\
\hline Cacau & 3 & 3 & 3 & 3 \\
\hline Açúcar mascavo & 9,5 & 9,5 & 9,5 & 9,5 \\
\hline Mel & 10 & 10 & 10 & 10 \\
\hline Glicose de milho & 10 & 10 & 10 & 10 \\
\hline Margarina & 4 & 4 & 4 & 4 \\
\hline Leite & 25 & 25 & 25 & 25 \\
\hline Canela & 1,6 & 1,6 & 1,6 & 1,6 \\
\hline Chá de cravo & 1,3 & 1,3 & 1,3 & 1,3 \\
\hline Bicarbonato & 0,75 & 0,75 & 0,75 & 0,75 \\
\hline Fermento & 0,1 & 0,1 & 0,1 & 0,1 \\
\hline
\end{tabular}

FBVCP: Farinha de banana verde cozida prata; FBVCN: Farinha de banana verde cozida nanicão; Padrão: 100\% trigo; A: 30\% FBVCP; B: 30\% FBVCN; C: 15\% FBVCP e 15\% FBVCN.

Técnica de preparo:

1. Peneirar, pesar e misturar todos os ingredientes secos: cacau, açúcar mascavo, canela e farinhas; 2. Acrescentar a margarina e misturar; 3. Acrescentar o mel e glicose de milho e misturar; 4. Adicionar os líquidos leite e chá de cravo e misturar; 5 . Por último, acrescentar o bicarbonato e fermento e misturar bem. Colocar em forminhas untadas; 6 . Assar por aproximadamente 12 minutos $/ 180^{\circ} \mathrm{C}$ em forno preaquecido; 7 . Após esfriar, fazer o banho de chocolate ao leite ou meio amargo, colocar em refrigeração por 20 minutos; 8 - Embalar e servir. 


\section{Análise sensorial dos produtos}

As análises sensoriais dos produtos seguiram os procedimentos descritos por Dutcosky, ${ }^{20}$ nos quais as amostras foram codificadas com algarismo aleatórios de três dígitos, oferecidas em blocos completos casualizados balanceados com as fichas: perfil do provador e do teste propriamente dito. Os provadores assinaram o Termo de Consentimento Livre e Esclarecido.

Teste de preferência (Ordenação): A preferência pelos pães de mel foi analisada através do teste de ordenação realizado com 37 provadores não treinados, selecionados de forma aleatória. Cada provador recebeu as quatro amostras de pães de mel (P, A, B e C) de aproximadamente $9 \mathrm{~g}$ cada e avaliaram o aspecto global.

Teste de aceitação: A aceitabilidade foi analisada através da escala hedônica de nove pontos, variando de gostei muitíssimo (pontuação máxima, 9) e desgostei muitíssimo (pontuação mínima, 1), realizada com 73 provadores não treinados consumidores potenciais do produto. Receberam três amostras de pães de mel (9 g cada) elaborados com as FBVC (A, B e C) e a escala hedônica para avaliarem o quanto gostaram ou quanto desgostaram de cada amostra para os atributos: aparência, aroma, textura, sabor e aspecto global.

\section{Análise estatística}

Os dados das análises física, química, físico-química e sensorial foram submetidos à analise de variância (ANOVA) seguida do teste de Tukey com significância ao nível de 5\%. Para o teste de preferência, foi utilizada para interpretação dos resultados a tabela de Friedman ${ }^{20}(\mathrm{p} \leq 0,05)$, e para o de aceitação, o critério para ser de boa aceitação foi de IA $\% \geq 70 \% \cdot{ }^{20}$ As análises foram feitas no software estatístico Statistical for windons versão 6.0.

\section{Resultados e Discussão}

Há relatos literários que frutos do mesmo gênero e espécie botânica ${ }^{4,5}$ apresentam propriedades culinária (propriedades de pasta e retrogradação), fisiológica e bioquímica distintas, demonstrando que as espécies abrigam variações no comportamento de diferentes genótipos à quantidade, forma e estruturas cristalinas, sobretudo do amido resistente. Por isso, objetivamos trabalhar com farinhas de banana verde obtidas da mesma espécie vegetal, porém de duas variedades de maior circulação no comércio varejista. 


\section{Análises física, química e físico-química das farinhas}

Foram utilizados como matéria-prima, aproximadamente, $16 \mathrm{~kg}$ de banana verde das duas variedades (prata e nanicão). A partir dos quais foram obtidos $8 \mathrm{~kg}$ de polpa de banana verde cozida, representando 52\% do fruto in natura. Após desidratação em estufa ventilada, obteve-se cerca de $3 \mathrm{~kg}$ (17\%) de FBVC, correspondendo ao rendimento total de $17 \%$ a partir do fruto in natura. Ambas as farinhas foram de coloração creme, aspecto homogêneo, mas a quantidade de semente na variedade prata era muito maior.

A composição química e físico-química das farinhas está descrita na Tabela 2.

Tabela 2. Composição química ( $\mathrm{g} \%$ ) e físico-química das farinhas produzidas de duas variedades de banana verde cozida. Rio de Janeiro-RJ, 2015.

\begin{tabular}{ccc}
\hline & \multicolumn{2}{c}{ Farinhas } \\
\cline { 2 - 3 } Parâmetros & FBVCP & FBVCN \\
\hline Umidade (\%) & $4,20^{\mathrm{a}}$ & $5,80^{\mathrm{b}}$ \\
Cinzas (\%) & $2,50^{\mathrm{a}}$ & $2,50^{\mathrm{a}}$ \\
Fibra alimentar (\%) & $0,54^{\mathrm{b}}$ & $3,80^{\mathrm{a}}$ \\
Proteínas*(\%) & $4,93^{\mathrm{a}}$ & $4,92^{\mathrm{a}}$ \\
Lipídeos (\%) & $0,90^{\mathrm{a}}$ & $0,80^{\mathrm{a}}$ \\
AR* $(\%)$ & $20,43^{\mathrm{a}}$ & $10,40^{\mathrm{b}}$ \\
Carboidratos**(\%) & $76,53^{\mathrm{a}}$ & $61,75^{\mathrm{b}}$ \\
Acidez titulável $(\mathrm{p} / \mathrm{v})$ & $7,00^{\mathrm{b}}$ & $13,50^{\mathrm{a}}$ \\
pH & $5,30^{\mathrm{a}}$ & $5,00^{\mathrm{b}}$
\end{tabular}

FBVCP: Farinha de banana verde cozida prata; FBVCN: Farinha de banana verde cozida nanicão; *AR: Amido resistente, foi calculado a partir de Ramos et al., ${ }^{4}$. ${ }^{*}$ Calculado por diferença $\{100$ - (Umidade, cinzas, proteínas, lipídeos, fibra alimentar e AR)\}. Valores seguidos de letras iguais na mesma linha não diferem entre si $(\mathrm{p}>0,05)$.

O teor de umidade das duas farinhas apresentou-se menor que o recomendado na legislação, o qual é de, no máximo, $14 \% \%^{21}$ para farinha de trigo. Fasolin et al..$^{22}$ também relataram teor de umidade menor em farinha de banana verde que o constatado na legislação. Segundo Fernandes et al., ${ }^{23}$ farinhas com umidade acima de $14 \%$ possibilitam o desenvolvimento e crescimento de microrganismo, como fungos, e a redução da estabilidade da farinha. Sendo assim, a quantidade determinada nas FBBV contribui para a estabilidade do produto e sua segurança microbiológica. 
Em relação ao Resíduo Mineral Fixo (Cinzas), os resultados para os dois tipos de farinha produzidos neste estudo apresentaram-se maiores que os descritos na legislação da Anvisa, ${ }^{21}$ o qual é de até 2,15 g\% para farinha integral, porém próximo ao de Medeiros et al. ${ }^{24} \mathrm{em}$ sua formulação de farinha de banana verde. Pelo teor constatado nas análises, as FBVC podem ser classificadas de farinha integral.

Para fibra insolúvel, o valor encontrado na $\operatorname{FBVCP}(0,54 \mathrm{~g} / 100 \mathrm{~g})$ mostrou-se abaixo do verificado por Borges, Pereira e Lucena ${ }^{6}$ em farinha de banana verde (1,01 g/100 g). Já para os teores da FBVCN, apresentou-se três vezes superior ao descrito pelos autores (3,80/100 g). Aspecto importante, segundo Resolução $n^{0}$ 54, de 12 de novembro de 2012, da Anvisa, já que se pode considerar alimento fonte deste componente. ${ }^{25}$

Verificaram-se valores do teor proteico superior às farinhas de cereais: milho $=6,94 \mathrm{~g} \% \mathrm{e}$ arroz $=6,7 \mathrm{~g} \%$, e muito próximo aos teores das farinhas de semolina e trigo especial (12,7 e 9,4 $\mathrm{g} \%$ ), respectivamente, ${ }^{26}$ e próximos aos encontrados por Borges, Pereira e Lucena ${ }^{3}$ para farinha de banana verde.

O teor de lipídios 0,90 g/100 g para FBVCP e 0,80 g/100 g para FBVCN apresentou-se próximo ao encontrado por Borges, Pereira e Lucena ${ }^{6}$ em farinha de banana verde $(0,88 \mathrm{~g} / 100 \mathrm{~g})$, porém abaixo do referido por Fasolin et al. ${ }^{22}$ para o mesmo tipo de farinha ( $\left.1,89 \mathrm{~g} / 100 \mathrm{~g}\right)$. O baixo teor de lipídios encontrado nas FBVC correlaciona-se bem com menor possibilidade de reações de deterioração por oxidação lipídica, aumentando a estabilidade do produto no armazenamento, potencializada com o reduzido teor de umidade e valor energético encontrado nas farinhas.

Há uma expressiva quantidade de amido resistente (AR) nas farinhas obtidas: FBVC-prata e nanicão, com 20,43 e 10,40 g\%, respectivamente. Segundo Freitas \& Tavares, ${ }^{6}$ a banana verde constitui uma excelente fonte de amido resistente nativo, com predominâncias dos grânulos de formas ovais e alongados com tamanhos diferenciados, existindo polimorfismo entre as variedades de bananas, os quais podem ter interesse em aplicações tecnológicas e nutricionais. Quanto aos carboidratos, são elevados, porém complexos.

A acidez titulável das duas farinhas (7,00 p/v para FBVCP e 13,50 p/v para FBVCN) mostrou-se acima do máximo estabelecido na legislação ${ }^{21}$ para diversos tipos de farinha (máximo de 5,0 p/p para farinhas de centeio e de fubá). Os valores de $\mathrm{pH}$ apresentaram-se próximos ao referido por Borges, Pereira e Lucena ${ }^{6}$ em farinha de banana verde $(\mathrm{pH}=5,30)$. Esses fatos são explicados pela lixiviação dos ácidos orgânicos muito presentes na matriz vegetal, sobretudo de frutas e hortaliças, quando submetidos ao tratamento hidrotérmico.

Desse modo, estas farinhas apresentam perfis químico e físico-químico satisfatórios para estabilidade antes e durante o armazenamento, bem como para sua utilização. 
Análises física, química e físico-química dos produtos

As características físicas estão descritas na Tabela 3, e a composição química e físico-química, na Tabela 4.

Tabela 3. Características físicas dos pães de mel produzidos com farinhas de duas variedades de banana verde cozida, Rio de Janeiro, Rio de Janeiro, 2015.

\begin{tabular}{|c|c|c|c|c|}
\hline Parâmetros & PADRÃO & A & $\mathrm{B}$ & $\mathrm{C}$ \\
\hline \multicolumn{5}{|l|}{ Peso $(g)$} \\
\hline pré-cocção & $7,30^{\mathrm{b}}$ & $7,00^{\mathrm{a}}$ & $7,00^{\mathrm{a}}$ & $7,00^{\mathrm{a}}$ \\
\hline pós-cocção & $6,10^{\mathrm{a}}$ & $6,30^{\mathrm{a}}$ & $6,50^{\mathrm{a}}$ & $6,10^{\mathrm{a}}$ \\
\hline \multicolumn{5}{|l|}{ Altura (cm) } \\
\hline pré-cocção & $0,90^{\mathrm{a}}$ & $0,90^{\mathrm{a}}$ & $0,90^{\mathrm{a}}$ & $0,90^{\mathrm{a}}$ \\
\hline pós-cocção & $2,10^{\mathrm{a}}$ & $1,80^{\mathrm{bc}}$ & $1,90^{\mathrm{b}}$ & $1,60^{\mathrm{c}}$ \\
\hline \multicolumn{5}{|l|}{ Diâmetro (cm) } \\
\hline pré-cocção & $3,0^{\mathrm{a}}$ & $3,0^{\mathrm{a}}$ & $3,0^{\mathrm{a}}$ & $3,0^{\mathrm{a}}$ \\
\hline pós-cocção & $2,80^{\mathrm{a}}$ & $2,80^{\mathrm{a}}$ & $2,90^{\mathrm{a}}$ & $2,90^{\mathrm{a}}$ \\
\hline Densidade (g/mL) & $0,70^{\mathrm{b}}$ & $0,90^{\mathrm{b}}$ & $1,50^{\mathrm{a}}$ & $0,70^{\mathrm{b}}$ \\
\hline Fator térmico & $0,83^{\underline{a}}$ & $0,90^{\mathrm{a}}$ & $0,93^{\mathrm{a}}$ & $0,89^{\mathrm{a}}$ \\
\hline Rendimento (\%) & $83,00^{\mathrm{a}}$ & $90,00^{\mathrm{a}}$ & $93,00^{\mathrm{a}}$ & $89,00^{\mathrm{a}}$ \\
\hline \multicolumn{5}{|c|}{ Banho de chocolate } \\
\hline Peso $(g)$ & $9,90^{\underline{a}}$ & $9,80^{\underline{a}}$ & $10,20^{\mathrm{a}}$ & $9,70^{\mathrm{a}}$ \\
\hline Altura (cm) & $2,30^{\mathrm{a}}$ & $2,00^{\mathrm{b}}$ & $2,20^{\mathrm{ab}}$ & $1,70^{c}$ \\
\hline Diâmetro (cm) & $2,80^{\mathrm{b}}$ & $3,00^{\mathrm{ab}}$ & $3,10^{\mathrm{a}}$ & $3,00^{\mathrm{ab}}$ \\
\hline Fator térmico & $1,62^{\underline{a}}$ & $1,56^{\underline{a}}$ & $157^{\mathrm{a}}$ & $1,57^{\mathrm{a}}$ \\
\hline Rendimento (\%) & $162,00^{\mathrm{a}}$ & $156,00^{\mathrm{a}}$ & $157,00^{\mathrm{a}}$ & $157,00^{\mathrm{a}}$ \\
\hline
\end{tabular}

Padrão: 100\% trigo; A: 30\% Farinha de banana verde cozida prata-FBVCP; B: 30\% Farinha de banana verde cozida nanicão-FBVCN; C: 15\% FBVCP e 15\% FBVCN. Valores seguidos de letras iguais na mesma linha não diferem entre si $(\mathrm{p}>0,05)$. 
Tabela 4. Composição química (\%) e físico-química dos pães de mel produzidos com farinhas de duas variedades de banana verde cozida, Rio de Janeiro-RJ, 2015.

\begin{tabular}{ccccc}
\hline Parâmetros & PADRÃO & A & B & C \\
\hline Umidade $(\%)$ & $17,40^{\mathrm{ab}}$ & $18,00^{\mathrm{a}}$ & $16,80^{\mathrm{b}}$ & $17,40^{\mathrm{ab}}$ \\
Cinzas $(\%)$ & $1,30^{\mathrm{c}}$ & $1,40^{\mathrm{b}}$ & $1,40^{\mathrm{b}}$ & $1,60^{\mathrm{a}}$ \\
Fibras $(\%)$ & $6,41^{\mathrm{ab}}$ & $4,38^{\mathrm{ab}}$ & $7,35^{\mathrm{a}}$ & $1,46^{\mathrm{b}}$ \\
Proteínas* $(\%)$ & $10,34^{\mathrm{a}}$ & $9,85^{\mathrm{a}}$ & $9,85^{\mathrm{a}}$ & $9,85^{\mathrm{a}}$ \\
Lipídeos* $(\%)$ & $9,99^{\mathrm{a}}$ & $10,04^{\mathrm{a}}$ & $10,04^{\mathrm{a}}$ & $10,04^{\mathrm{a}}$ \\
AR*** $(\%)$ & 0,00 & $3,12^{\mathrm{c}}$ & $6,13^{\mathrm{a}}$ & $4,62^{\mathrm{b}}$ \\
Carboidratos** $(\%)$ & $53,64^{\mathrm{a}}$ & $45,00^{\mathrm{b}}$ & $39,61^{\mathrm{c}}$ & $46,54^{\mathrm{b}}$ \\
Acidez Titulável $(\mathrm{p} / \mathrm{v})$ & $1,10^{\mathrm{b}}$ & $1,10^{\mathrm{b}}$ & $1,70^{\mathrm{a}}$ & $1,10^{\mathrm{b}}$ \\
pH & $7,10^{\mathrm{ab}}$ & $7,11^{\mathrm{ab}}$ & $7,12^{\mathrm{a}}$ & $7,03^{\mathrm{b}}$ \\
\hline
\end{tabular}

Padrão: 100\% trigo; A: 30\% Farinha de banana verde cozida prata-FBVCP; B: 30\% Farinha de banana verde cozida nanicão-FBVCN; C: 15\% FBVCP e 15\% FBVCN; *Calculado a partir de Fansolin et al., ${ }^{22}$ e Philippi. ${ }^{26} *$ *Calculado por diferença das demais análises químicas; ***AR: Amido resistente, foi calculado a partir de Ramos et al., ${ }^{4}$. Valores seguidos de letras iguais na mesma linha não diferem entre si $(p>0,05)$.

Em relação às características físicas dos pães de mel, não houve nenhuma diferença $(p>0,05)$ entre os parâmetros analisados antes e após o banho de chocolate, exceto na altura pós-cocção antes e após o banho de chocolate. Observa-se que o pão de mel Padrão produzido apenas com farinha de trigo apresentou altura pós-cocção maior que os outros pães de mel que tiveram a adição das farinhas. Essa diferença de altura pode ser explicada pelo elevado conteúdo de fibras nas farinhas, o que impede a expansão da massa durante a cocção. Em Perez e Germani, ${ }^{27}$ resultados semelhantes foram encontrados ao desenvolverem biscoitos do tipo salgado com a adição de farinha de berinjela em diferentes porcentuais.

Vilhalva et al. ${ }^{28}$ também encontraram evento similar em pães confeccionados com farinha da casca de maracujá (FCM). À medida que aumentou a concentração da FCM, em substituição à farinha de trigo, os pães apresentaram menor volume.

Em relação à umidade apresentada pelos diferentes produtos, quando comparados com o teor de umidade preconizado para diversos tipos de pães, estava dentro do estabelecido pela legislação vigente, ${ }^{21}$ tendo sido encontrada diferença $(\mathrm{p} \leq 0,05)$ entre as formulações A e B, desenvolvidas com FBVCP e FBVCN, respectivamente. A formulação A obteve o maior porcentual entre todas as formulações (18\%), sendo seguida pela formulação Padrão e pela C, ambas apresentando 17,40\%. O menor teor de umidade foi demonstrado pelo produto B, com cerca de $16,80 \%$ de umidade. 
Menores teores de umidade foram observados nos pães de mel de maior teor de amido resistente, o que se justifica pela propriedade de pouca adsorção de água do amido resistente em produtos. ${ }^{29}$

Quanto à análise de resíduo mineral fixo (RMF) ou cinzas, os produtos desenvolvidos com farinhas de banana verde apresentaram maiores teores de RMF quando comparadas à formulação padrão, o que se relaciona intimamente com o teor significativo observado para as farinhas das variedades prata e nanicão. O estudo de Borge, Pereira e Lucena ${ }^{6}$ mostrou que a farinha de banana proporciona ampla composição mineral, contando com potássio, fósforo cálcio, magnésio, enxofre, nitrogênio, boro, cobre, manganês, zinco e ferro, sendo sua inclusão indicada para o desenvolvimento de produtos com maior valor nutricional. A análise dos produtos mostrou porcentual de 1,60\% para a formulação C, seguida pelas formulações A e B, com 1,40\%, e, por último, pela formulação Padrão, com 1,30\%. A diferença foi considerada significativa entre a formulação Padrão e todos os tipos de formulações com as farinhas. Houve também diferença $(\mathrm{p} \leq 0,05)$ entre as formulações com apenas $30 \%$ de FBBV e a formulação C, elaborada com ambos os tipos de farinhas.

A análise de fibra alimentar total mostrou que houve diferença $(p \leq 0,05)$ entre os pães de mel da formulação PADRÃO e da C. A formulação B obteve maior porcentual, 7,35\%, seguida pela PADRÃO, com 6,41\%, pela A, 4,38\% e, com o menor porcentual, pela C, 1,46\%. Segundo a legislação, ${ }^{20} \mathrm{um}$ alimento é considerado fonte de fibras alimentares quando tem, no mínimo, 3\%, e alto teor de fibras quando têm, no mínimo, 6\%, logo, as formulações B e PADRÃO são ricas em fibras e a formulação A é fonte de fibra. Em Possamai, Waszczynskyj \& Possamai, ${ }^{30}$ foram encontrados resultados semelhantes entre o pão de mel enriquecido com farelo de trigo, que obteve 6,04\%, e o pão de mel enriquecido com linhaça, 8,23\%, logo, são alimentos com alto teor de fibras. Visto que nas embalagens de pães de mel vendidos no comércio observa-se que o valor de fibra alimentar varia de $0 \%$ a $1 \% .{ }^{29}$ Assim sendo, pode-se comprovar que as formulações desenvolvidas neste estudo foram enriquecidas com as farinhas das duas variedades de banana, tornando-se produtos com alto teor de fibras, exceto a C.

Quanto às análises de proteína e lipídios, ainda na tabela 4, todos os pães de mel elaborados apresentaram valores similares $(\mathrm{p}>0,05)$

Na análise do AR dos produtos, a formulação B teve o maior porcentual, 6,13\%, seguida pela C, 4,62\%, e pela A, 3,12\%. Segundo Freitas e Tavares, ${ }^{5}$ a farinha de banana verde tem elevado teor de amido, sendo $80 \%$ desse de AR de reduzido potencial calórico, o qual participa efetivamente na prevenção de doenças crônicas e distúrbios metabólicos e intestinal. . $^{10,11,16,31}$

Além desses benefícios, a aplicação de amido resistente é apropriada para a maioria dos produtos de baixa umidade, propiciando melhor aparência e textura e contribuindo para melhoria de expansão e crocância de produtos, ${ }^{32}$ sobretudo de panificação, como o desenvolvido no presente trabalho. 
O pão de mel formulado com a farinha da variedade nanicão (produto B) apresentou acidez titulável e pH aumentados $(\mathrm{p} \leq 0,05)$ em decorrência da maior quantidade de sementes na polpa desse fruto $^{5}$ e da formação de compostos voláteis com características ácidas durante o processo de cocção. ${ }^{33}$

\section{Análises sensoriais dos produtos}

Em relação ao teste de preferência, a maioria dos avaliadores eram do sexo feminino (71\%), tinham mais de 18 anos (87\%), ensino superior incompleto (58\%) e apenas $5 \%$ já consumiram algum produto feito da PBV ou da FBVC. Segundo a Tabela 5, todas as amostras foram igualmente preferidas.

Tabela 5. Ranking do teste sensorial preferência ordenação das quatro formulações de pães de mel, Rio de Janeiro-RJ, 2015.

\begin{tabular}{ccccc}
\hline & \multicolumn{4}{c}{ Formulações } \\
\cline { 2 - 5 } & PADRÃO & A & B & C \\
\hline Ranking obtidos & $31^{\mathrm{a}}$ & $25^{\mathrm{a}}$ & $26^{\mathrm{a}}$ & $39^{\mathrm{a}}$ \\
\hline
\end{tabular}

Padrão: 100\% trigo; A: 30\% Farinha de banana verde cozida prata-FBVCP; B: 30\% Farinha de banana verde cozida nanicão-FBVCN; C: $15 \%$ FBVCP e $15 \%$ FBVCN. Valores seguidos de letras iguais na mesma linha não diferem entre si $(\mathrm{p}>0,05)$, segundo teste de Friedman.

Possamai, Waszczynskyj \& Possamai ${ }^{30}$ enriqueceram pães de mel com farelo de trigo, linhaça, soja e aveia, e o resultado foi diferente: os pães de mel enriquecidos com fibra alimentar (20\% de farelo de trigo e $20 \%$ de linhaça) foram os preferidos, e o de $20 \%$ de aveia e o padrão (100\% de farinha de trigo) foram igualmente preferidos, ficando em terceiro lugar e o menos preferido, o de $20 \%$ de farinha de soja.

No teste de aceitação, a maioria também era do sexo feminino (68\%), entre 18-25 anos (57\%), cursando o ensino superior (59\%). A frequência de consumo de pão de mel por parte dos provadores foi, no mínimo, quinzenalmente, enquanto a de maior frequência de consumo ficou com os biscoitos, bolos e chocolates. 
Tabela 6. Nota média e Índice de Aceitabilidade (IA\%) dos atributos do teste de aceitação para as formulações de pães de mel, Rio de Janeiro-RJ, 2015.

\begin{tabular}{ccccccc}
\hline Atributos & \multicolumn{2}{c}{ A } & \multicolumn{2}{c}{ B } \\
\hline Aparência & $7,64 a$ & $84,85 a$ & $7,68 \mathrm{a}$ & $85,35 \mathrm{a}$ & $7,89 \mathrm{a}$ & $87,63 \mathrm{a}$ \\
Aroma & $8,09 \mathrm{a}$ & $89,90 \mathrm{a}$ & $8,00 \mathrm{a}$ & $88,87 \mathrm{a}$ & $8,23 \mathrm{a}$ & $91,41 \mathrm{a}$ \\
Textura & $7,40 \mathrm{a}$ & $82,32 \mathrm{a}$ & $7,89 \mathrm{a}$ & $87,63 \mathrm{a}$ & $7,68 \mathrm{a}$ & $85,35 \mathrm{a}$ \\
Sabor & $7,59 \mathrm{a}$ & $84,34 \mathrm{a}$ & $8,09 \mathrm{a}$ & $89,90 \mathrm{a}$ & $8,05 \mathrm{a}$ & $89,40 \mathrm{a}$ \\
Aspecto global & $7,66 \mathrm{a}$ & $85,10 \mathrm{a}$ & $8,02 \mathrm{a}$ & $89,14 \mathrm{a}$ & $7,93 \mathrm{a}$ & $88,13 \mathrm{a}$ \\
\hline
\end{tabular}

Padrão: 100\% trigo; A: 30\% Farinha de banana verde cozida prata-FBVCP; B: 30\% Farinha de banana verde cozida nanicão-FBVCN; C: 15\% FBVCP e 15\% FBVCN. Valores seguidos de letras iguais na mesma linha não diferem entre si $(\mathrm{p}>0,05)$.

Os resultados do teste de aceitação (Tabela 6) demonstraram escores médios dos atributos para as três formulações superiores a 7 (gostei moderadamente), situando-se na zona de aceitação pelos provadores, sendo o Índice de Aceitabilidade maior que 70\%, indicando como satisfatória a aceitação dos produtos elaborados com as farinhas em todos os atributos. Resultados semelhantes foram encontrados em Fasolin et al., ${ }^{22}$ que relataram boa aceitação de biscoito produzido com $10 \%$ e $20 \%$ de farinha de banana verde, sem diferença $(\mathrm{p} \leq 0,05)$ entre este e o padrão $(100 \%$ de farinha de trigo). Já Ritter \& Mallman ${ }^{29}$ relataram aceitação de $69 \%$ de pão de mel integral confeccionado com farelo e fibra de trigo.

Gilbert et al. ${ }^{36}$ descreveram que o elevado teor de AR proveniente de amido de milho modificado, quando adicionado em cookies, contribuiu para a redução de carboidratos digeríveis sem alterar as características sensoriais do produto.

Destituídas de sabor, as farinhas podem ser incorporadas à massa de pão de mel, não alterando as propriedades sensoriais, sobretudo aroma, sabor e cor, além de supri-la de vitaminas, minerais e de elevado teor de amido resistente (AR), fato constatado nos testes sensoriais e como potencialidade de ingrediente funcional. ${ }^{11,35,37}$

\section{Conclusão}

As farinhas de banana verde cozidas das variedades prata e nanicão podem ser usadas como fontes de fibra alimentar e amido resistente, porém é notório que as variedades das bananas abrigam diferenciações nesses teores. No entanto, ambas mostraram-se capazes de agregar valor funcional e nutricional aos produtos a partir delas desenvolvidos. 
Os pães de mel elaborados com as farinhas são fontes em fibra alimentar e amido resistente e não apresentaram alterações nas características de crescimento da massa e tampouco nas características sensoriais dos produtos, a saber: sabor, aroma, cor e textura, com boa aceitação, representando, assim, alternativas interessantes ao pão de mel PADRÃO.

\section{Colaboradores}

Todos os autores contribuíram na concepção e desenho do estudo, análise de dados e redação final. Conflito de Interesses: Os autores declaram não haver conflito de interesses.

\section{Referências}

1. Faisant N, Planchot V, Kozlowski F, Pacourent M-P, Colonna P, Champ M. Resistant starch determination adapted to products containing high level of resistant starch. Scinces des Aliments 1995; 15(1):83-89.

2. Teixeira MAV, Ciacco CF, Tavares DQ, Bonezzi AN. Ocorrência e caracterização do amido resistente de milho e de banana. Ciênc Tecnol Aliment.1998; 18(2):246-253.

3. Qi X, Tester RF. Effect of native starch granule size on susceptibility to amylase hidrolysis. Starch/ Stärke 2016; 68:807-810.

4. Ramos DP, Leonel M, Leonel S. Amido resistente em farinhas de banana verde. Alim Nutr. 2009; 20(3):479-483.

5. Freitas MCJ, Tavares DQ. Caracterização do grânulo de amido de bananas (musa AAA- Nanicão e Musa AAB- Terra). Ciênc Tecnol Aliment. 2005; 25(2):217-222.

6. Borges AM, Pereira J, Lucena EMP. Caracterização da farinha de banana verde. Ciênc Tecnol Aliment. 2009; 29(2):333-339.

7. Borges MTMR. Potencial vitamínico da banana verde e produtos derivados [tese]. [Campinas]: Universidade Estadual de Campinas, Faculdade de Engenharia de Alimentos; 2003.

8. Walter M, Silva LP, Emanuelli T. Amido resistente: características físico-químicas, propriedades fisiológicas e metodologias de quantificação. Ciência Rural 2005; 35(4):974-980.

9. Machado NCR, Sampaio RC, Lima JCR. Efeitos do amido resistente da biomassa de banana verde. [Trabalho de Conclusão de Curso]. Goiás: Faculdade União de Goyazes; 2013.

10. Freitas MCJ. Dietas ricas em amido resistente de bananas verdes (Musa AAA-Nanicão e Musa AABTerra) promovem alterações na função intestinal, no metabolismo lipídico e glicídico e na microbiota intestinal. [Tese]: [Campinas]: Universidade Estadual de Campinas, Faculdade de Engenharia de Alimentos; 2000.

11. Ashwar BA, Gani A, Shah A, Wani IA, Massoodi FA. Preparation, health benefits and applications of resistant starch: a review. Starch/Stärke 2016; 68:287-301. 
12. Dronamraju SS, Coxhead JM, Kelly SB, Burn J, Mathers JC. Cell kinetics and gene expression changes in colorectal cancer patients given resistant starch: a randomised controlled trial. Gut 2009; 58:413-420.

13. Milhoranse K, Martrins N, Freitas MCJ. Desenvolvimento de farinha de biomassa de banana verde (Musa Cavendishi) e sua aplicação em biscoito. Journal of Fruits and Vegetables 2015; 1(2):406-411.

14. Wang Y, Zhang M, Mujumdar AS. Influence of green banana flour substitution for cassava starch on the nutrition color, texture and sensory quality in two types of snacks. LWT-Food Science and Technology 2012; 47(1):175-182.

15. Zandonadi, RP, Botelho RB, Gandolfi L, Ginani JS, Montenegro FM, Pratesi R, et al. Green banana pasta: an alternative for gluten-free diets. J Acad Nutr Diet 2012; 112(7):1068-1072.

16. Sajilata MG, Singhal RS, Kulkarni, PR. Resistant starch: a review. Comprehensive Reviews in Food Science and Food Safety 2006; 5(1):1-17.

17. Companhia de Entrepostos e Armazéns Gerais de São Paulo. Programa brasileiro para a modernização da horticultura \& produção integrada de frutas. Normas de Classificação de Banana. São Paulo: CEAGESP; 2006.

18. Silva MR, Silva MS, Martins KA, Borges S. Utilização tecnológica dos frutos de jatobá-do-cerrado e de jatobá-da-mata na elaboração de biscoitos fontes de fibra alimentar e isentos de açúcares. Ciênc Tecnol Aliment. 2001; 21(2):176-182.

19. Instituto Adolfo Lutz. Normas analíticas do instituto Adolfo Lutz: métodos químicos e físicos para análise de alimentos. 4 ed. São Paulo: IAL; 2005. 1018 p.

20. Dutcosky SD. Análise sensorial de alimentos. 4 ed. Curitiba: Champagnat; 2013. 531 p.

21. Brasil. Agência Nacional de Vigilância Sanitária. Resolução CNNPA n. 12 de 1978 [Internet]. Diário Oficial da União 24 jul. 1978. [acesso em: 16 dez. 2015]. Disponível em: http://www.anvisa.gov.br/ anvisalegis/resol/12_78.htm

22. Fasolin LH, Almeida GC, Castanho PS, Netto-Oliveira ER. Biscoitos produzidos com farinha de banana: avaliações química, física e sensorial. Ciênc Tecnol Aliment. 2007; 27(3):524-529.

23. Fernandes AF, Pereira J, Germani R, Oiano-Neto J. Efeito da substituição parcial da farinha de trigo por farinha de casca de batata (Solanum tuberosum Lineu). Ciênc Tecnol Aliment. 2008; 28(Supl.):56-65.

24. Medeiros MJ, Oliveira PAC, Souza JML, Silva RF, Souza ML. Composição química de misturas de farinhas de banana verde com castanha-do-Brasil. Rev Inst Adolf Lutz 2010; 69(3):396-402.

25. Brasil. Agência Nacional de Vigilância Sanitária. Resolução RDC n0 54, de 12 de novembro de 2012. Dispõe sobre o Regulamento Técnico sobre Informação Nutricional Complementar. Diário Oficial da União 13 nov. 2012.

26. Philippi ST. Tabela de composição de alimentos: suporte para decisão nutricional. 3a ed. São Paulo: Manole; $2012.161 \mathrm{p}$.

27. Perez P, Germani R. Elaboração de biscoitos tipo salgado, com alto teor de fibra alimentar, utilizando farinha de berinjela (Solanum melongena, L.). Ciênc Tecnol Aliment. 2007; 27(1):186-192. 
28. Vilhalva DAA, Soares Junior MS, Moura CMA, Caliari M, Souza TAC, Silva FA. Aproveitamento da farinha de casca de mandioca na elaboração de pão de forma. Rev Inst Adolfo Lutz 2011; 70(4):514-521.

29. Ritter AL, Mallman F. Pão de mel integral fonte de fibras [Internet]. Lajeado, RS: Centro Universitário Univates; 2014. [acesso em: 01 abr. 2016]. Disponível em: https://www.univates.br/tecnicos/media/ artigos/Alessandra_Ritter.pdf

30. Possamai TN, Waszczynskyj N, Possamai JC. Pão de mel enriquecido com fibra alimentar. Visão Acadêmica 2009; 10(1):40-46.

31. Bianchi M. Benefícios da biomassa de banana verde na diminuição do risco de sobrepeso e/ou obesidade e suas comorbidades [Internet]. São Paulo: Baixada Santista, 2010. [acesso em: 09 dez. 2015]. Disponível em: http://www.valemaisalimentos.com.br/datafiles/imagens/files/TCC_Marcia_ Bianchi_.pdf

32. Pereira KD. Amido resistente, a última geração no controle de energia e digestão saudável. Ciênc Tecnol Aliment. 2007; 27(Supl.):88-92.

33. Soares WS, Rêgo MM, Rêgo ER, Barroso PA, Medeiros LRN. Caracterização de fruto e sementes em acessos de maracujá silvestre (Passiflora Foetida L.). Rev Bras Plantas Med. 2011; 13(Esp.):569-573.

34. Dan MCT. Avaliação da potencialidade da farinha de banana verde como ingrediente funcional: Estudo in vivo e in vitro. [Tese]. [São Paulo]: Universidade de São Paulo. Faculdade de Ciências Farmacêuticas. Programa de Pós-Graduação em Ciência dos Alimentos; 2011.

35. Ranieri LM, Delani TCO. Banana verde (Musa spp): obtenção da biomassa e ações fisiológicas do amido resistente. Revista UNINGÁ Review 2014; 20(3):43-49.

36. Giuberti G, Gallo A, Fortunati P, Rossi F. Influence of high amylose starch addition on in vitro starch digestibility and sensory characteristics of cookies. Starch/ Stärke 2016; 68:469-475.

37. Braga ED. Efeito da suplementação do amido resistente na obesidade e diabetes tipo 2. Revista Brasileira de Obesidade, Nutrição e Emagrecimento 2011; 5(28):277-283.

Recebido: $16 / 08 / 2016$

Revisado: 04/02/2017

Aceito: $14 / 04 / 2017$ 